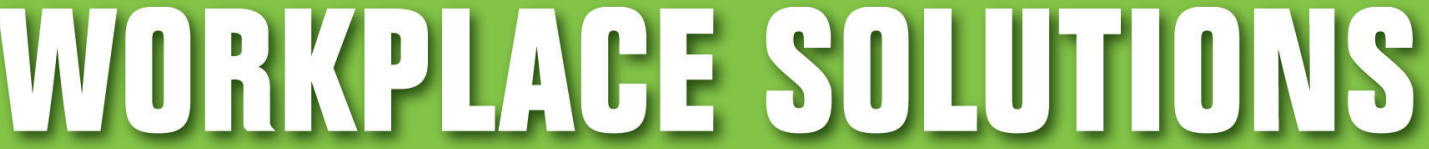

\section{Preventing Deaths and Injuries of Fire Fighters During Training Exercises}

\section{Summary}

Fire fighters are at risk of death or injury during training activities. The NIOSH Fire Fighter Fatality Investigation and Prevention Program (FFFIPP) recommends training in accordance with established standards to prevent life-threatening consequences.

\section{Description of Problem}

During the period from 2001 to 2014, the United States Fire Administration reported that approximately $11 \%$ (150 out of 1,396) of fire fighter line-of-duty deaths were training-related. The leading cause of training-related deaths was heart attacks (55\%), followed by traumatic injury (28\%). The remaining $17 \%$ were other types of cardiovascular disease and other diverse circumstances.

Physical fitness activities, apparatus/ equipment drills, and live-burn exercises were the three leading types of training-related activities associated with the fatalities [USFA 2015].

The role of the fire department has evolved over the years to encompass more than traditional fire suppression. Fire fighters respond to hazardous material incidents, combustible-metal fires, large-scale disasters, and terrorist events. They perform trench, high incline, and confined space rescues and provide emergency medical service calls. Even fire suppression has become multifaceted with changes in technology and the fireground environment. In addition, residential home fires have decreased approximately $50 \%$ over the past 40 years [National Fire Protection Association (NFPA) 2013a]. The expanded role and decrease in structure fire fighting experience of the fire fighter has made training a necessity for carrying out the mission of the fire service as safely as possible.

Given the inherent dangers of fire fighting, the importance of improving skill sets and proficiency cannot be overstated. Training is beneficial in a number of ways, including: (1) enabling fire fighters to become familiar with the strategies and tactics of fire fighting, (2) improving their responsiveness in performing essential tasks, (3) ensuring proficiency in the use of personal protective equipment and fire fighting equipment, and (4) fostering teamwork.

Inadequate training and training without safeguards can be life threatening to fire fighters. National consensus standards for training programs have been established for decades; however, some fire departments are not conduct- ing training in accordance with these established standards. The reasons can include budgetary constraints, time constraints, and/or a lack of understanding the standards and the benefits of complying with them. Legal precedent has established that a lack of understanding of the standards will not absolve the department of responsibility and accountability for a fire fighter injury or death during training.

\section{NIOSH FFFIPP}

During 2001 to 2015, 81 training-related fatalities were investigated by NIOSH through the Fire Fighter Fatality Investigation and Prevention Program. Of these fatalities, $66(81.5 \%)$ were cardiacrelated and $11(13.5 \%)$ were traumarelated. These investigations included 42 deaths due to physical fitness activities, 23 deaths due to apparatus/equipment drills, 10 deaths due to live-burn exercises, and 6 deaths due to other training-associated circumstances.

\section{Case Studies}

\section{Case 1}

On December 8, 2008, a 42-year-old lieutenant in a volunteer fire department died after completing live-fire training drills that were part of a certified Fire Fighter II training course (see Figure 1). 


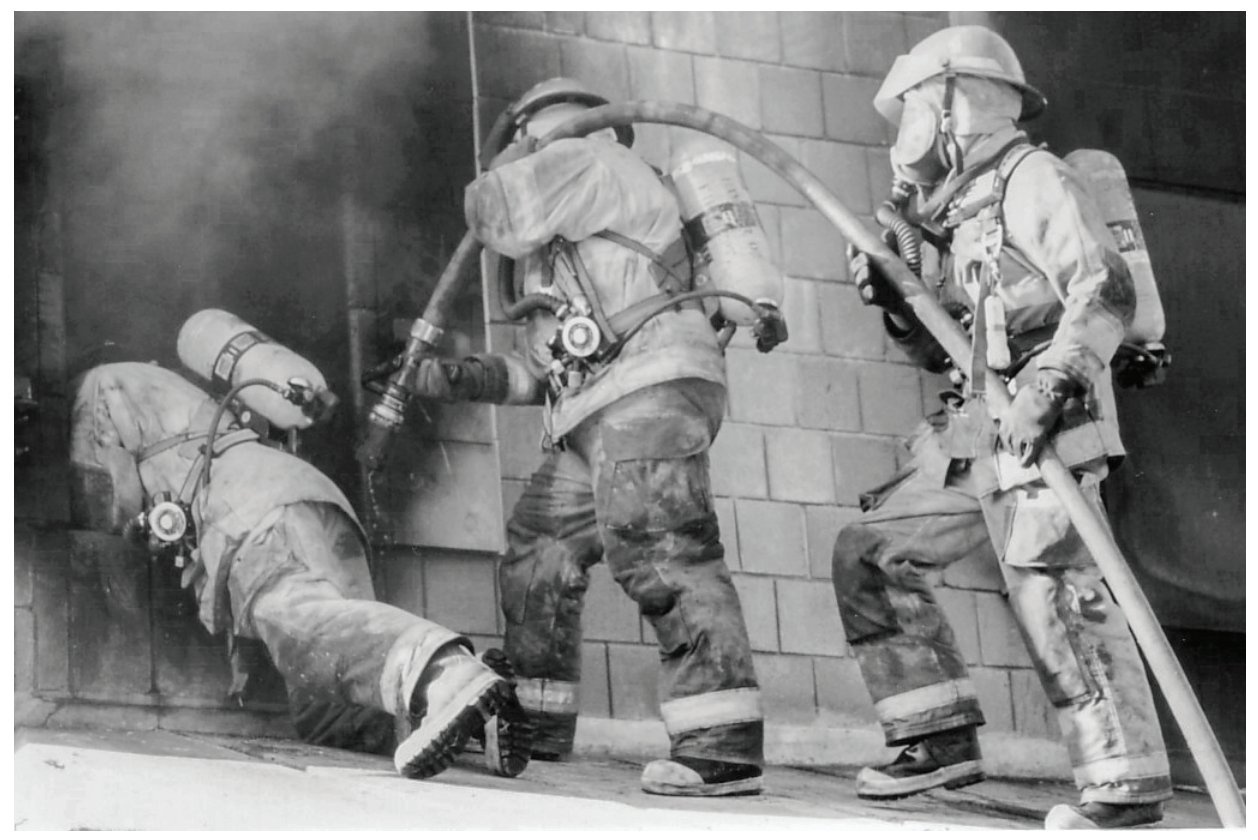

Figure 1. Live-fire training exercise.

The live-fire training involved two separate drills: (1) extinguishing a simulated natural gas fire and (2) discharging a foam line. The lieutenant complained of cold symptoms during the training and became short of breath during the last training evolution. Upon completion of the last drill, as other students cleaned up the hoselines, the lieutenant indicated that he was going to his fire department vehicle to rest. Approximately 10 minutes after leaving the training area, the lieutenant was found between the training site and his vehicle. Cardiopulmonary resuscitation was initiated by fire fighters followed by advanced life support by the arriving ambulance personnel. Despite these efforts the lieutenant died. The autopsy report listed the cause of death as "cardiac arrhythmia following strenuous physical activity (firefighter training) in individual with hypertensive and atherosclerotic cardiovascular disease." NIOSH investigators concluded that the physical exertion associated with the training drills performed in full personal protective equipment triggered the lieutenant's sudden cardiac death.

The fire department required a pre-employment medical evaluation for new members but had no annual requirement for incumbent members. The fire department had no formal wellness/fitness program or standard operating guidelines for training activities [NIOSH 2009a].

\section{Case 2}

On January 25, 2009, two male career fire fighters, age 28 and age 45, died after falling from an elevated aerial platform during a training exercise. The entire duty shift reported to a college dormitory for hands-on training to familiarize fire fighters with the operation of a new 95-foot midmount aerial platform truck (see Figure 2).

A group of four fire fighters were standing in the aerial platform, which was raised to the roof of an eight-story dormitory building at a local college. The platform became stuck on the concrete parapet wall at the top of the building. During attempts to free the platform, the top edge of the parapet wall gave way, and the aerial ladder sprang back from the top of the building and began whipping violently back and forth. Two of the four fire fighters standing in the platform were ejected. The fire fighters fell approximately 83 feet to the ground and died from their injuries. None of the four fire fighters were wearing safety harnesses.

The fire department in this incident was in the process of writing a new standard operating procedure (SOP) for the ladder truck. This SOP would have required the presence of a designated safety officer at the training exercise, which may have positively influenced the use of fall protection while on the platform [NIOSH 2009b].

\section{Controls}

Fire fighting is a dangerous occupation primarily because the environment is typically one that poses an immediate threat to life. The fire fighter's job is to gain control of a hazardous situation, which may require an extended period of time in a life-threatening environment. Fire fighter training activities, however, can be conducted in a controlled environment while still providing fire fighters with the needed hands-on experience. Fire departments should be aware of the hazards during training so they can plan, coordinate, and monitor activities to ensure the safety of all participants, including instructors and trainees. Standard operating procedures (SOPs) are a vital component to operating safely and effectively. Developing, implementing, and enforcing SOPs can significantly reduce the risk of injuries and deaths to fire fighters during training exercises. All persons involved in training exercises should maintain strict personal discipline and follow established safety, health, and operating guidelines just as in an actual event. 


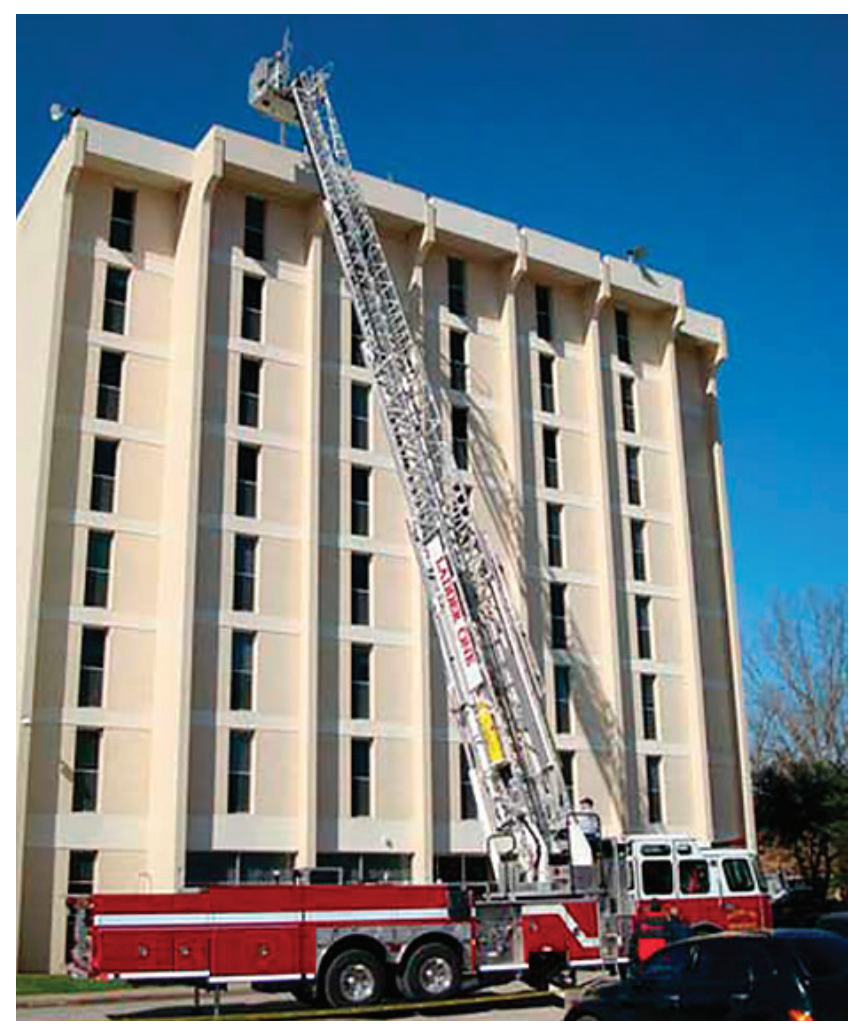

Figure 2. Aerial platform positioned at dormitory building to recreate incident scene.

To minimize risk when conducting training exercises, NIOSH recommends that fire departments and training participants take the following precautions.

\section{Recommendations for Fire Departments}

Before training, fire departments should do the following:

- Establish easy-to-understand, written SOPs for all training activities and ensure they are implemented and enforced.

- Conduct a hazard analysis before each training exercise to identify and address safety issues in advance.

- Ensure instructors are certified to NFPA 1041 [NFPA 2012a].

- Ensure that a sufficient number of certified instructors are available to conduct the specific training and maintain optimal student-to-instructor ratios, as per NFPA 1403 [NFPA 2012b].

- Establish a mandatory wellness/fitness program to ensure compliance with NFPA 1583 [NFPA 2015b].

- Ensure training participants have successfully completed all course prerequisites.

- Ensure that participants are screened to determine physical capacity and fitness to participate in the training.
- Medically clear fire fighters for respirator use and fullduty fire suppression by a physician knowledgeable about the physical demands of fire fighting, in accordance with NFPA 1582 [NFPA 2013b].

- Designate an individual, certified to NFPA 1521 [NFPA 2015a], to be the safety officer to review SOPs and monitor all training activities.

- Ensure that all new training curricula undergo a comprehensive safety review by training supervisors before implementation.

- Ensure that the training environment and facilities are inspected for hazards.

- Ensure that adequate time is allotted to safely carry out the training exercise.

- Ensure that all equipment, including personal protective equipment (PPE), is inspected and in good working order.

- Ensure that a 360-degree size-up is conducted for all training activities as would be done in an actual event.

- Establish and follow a pre-training checklist.

- Provide pre-training safety briefings, including a facility walk-through, for all participants.

During training, fire departments should do the following:

- Adopt and follow the North American Fire Training Directors Rules of Engagement for Safe Fire Service Training [NAFTD 2014].

- Ensure that sufficient numbers of fire suppression apparatus and equipment are readily available and inspected for live-burn training evolutions.

- Ensure that the proper types and adequate amounts of extinguishing agents are available for live-burn training evolutions.

- Ensure adequate space is provided for proper placement of all necessary apparatus.

- Ensure that all established NFPA standards and fire department procedures are followed.

- Monitor participants' physical stress and watch for signs of overexertion.

- Establish and maintain a rehab area stocked with appropriate hydration and nutrition supplies per NFPA 1584 [NFPA 2015c].

- Ensure all training participants wear the appropriate personal protective equipment at all times.

- Ensure that appropriate personnel (e.g., rapid intervention team) and equipment are available for assistance, rescue, emergency treatment, and transport. 
- Ensure that a fully staffed and equipped vehicle (e.g., Advanced Life Support ambulance) is on scene and ready to respond in case of an emergency.

- Provide adequate supervision and monitoring of activities by the training instructors.

- Maintain strict on-scene training discipline, adhering to established safety protocols, in accordance with NFPA 1403 and NFPA 1584 [NFPA 2012b, 2015c].

- Require the use of sunscreen if prolonged exposure to the sun is anticipated.

After training, fire departments should do the following:

- Ensure that participants, PPE, equipment, and the inside of the apparatus are adequately decontaminated before leaving the training site, particularly if live fire training was conducted.

- Conduct an evaluation of the training to document any potential issues that may have occurred, in accordance with the applicable NFPA standards (e.g., NFPA 1403 and NFPA 1584 [NFPA 2012b, 2015c]).

\section{Recommendations for Training Participants}

Prior to training, participants should do the following:

- Participate in a mandatory wellness/fitness program in compliance with NFPA 1583 [NFPA 2015b].

- Know the potential hazards of training exercises, such as toxins, explosive materials, falls and entanglements, and indicators of structural collapse, flashover, and backdraft.

- Be aware of emergency exit routes and alternative emergency escape plans.

- Understand your role in the exercise.

- Complete all course prerequisites for the specific training.

During training, participants should do the following:

- Conduct the training exercise according to established fire department SOPs and applicable NFPA standards.

- Maintain personal discipline and accountability for actions during training exercises.

- Recognize the signs and symptoms of personal medical emergencies and know the appropriate course of action.

- Personnel experiencing a medical issue during training should immediately self-report and be formally evaluated by trained medical personnel.

After training, participants should:

- Decontaminate PPE and the inside of the apparatus prior to leaving the training site, particularly if live fire training was conducted.

- Adequately wipe their skin using cleansing wipes.

\section{Acknowledgments}

Principal contributors to this publication were Matt Bowyer, Virginia Miles, Tommy Baldwin, and Thomas Hales, NIOSH FFFIPP; Linda Frederick, NIOSH Office of the Director; Stephen Berardinelli, U.S. Public Health Service; and John S. Jackson, Department of the Navy. Rita Fahy, National Fire Protection Association, provided the NFPA data.

\section{References}

NAFTD [2014]. Rules to live by: North American fire training directors http://naftd.org/Documents/Rules\%20You\%20Can\%20 Live\%20By.pdf.

NFPA [2012a]. NFPA 1041 standard for fire service instructor professional qualifications. Quincy, MA: National Fire Protection Association.

NFPA [2012b]. NFPA 1403 standard on live fire training evolutions. Quincy, MA: National Fire Protection Association.

NFPA [2013a] Home fires. Quincy, MA: National Fire Protection Association, http://www.nfpa.org/research/reports-andstatistics/fires-by-property-type/residential.

NFPA [2013b]. NFPA 1582 standard on comprehensive occupational medical program for fire departments. Quincy, MA: National Fire Protection Association.

NFPA [2015a]. NFPA 1521 standard for fire department safety officer professional qualifications. Quincy, MA: National Fire Protection Association.

NFPA [2015b]. NFPA 1583 standard on health-related fitness programs for fire department members. Quincy, MA: National Fire Protection Association.

NFPA [2015c]. NFPA 1584 standard on the rehabilitation process for members during emergency operations and training exercises. Quincy, MA: National Fire Protection Association.

NIOSH [2009a]. Lieutenant suffers a fatal cardiac event after completing live-fire training-Wisconsin. Morgantown, WV: U.S. Department of Health and Human Services, Centers for Disease Control and Prevention, National Institute for Occupational Safety and Health, Fatality Assessment and Control Evaluation (FACE) Report F2009-16, https://www.cdc.gov/niosh/fire/ reports/face200916.html.

NIOSH [2009b]. Two career fire fighters die after falling from elevated aerial platform-Texas. Morgantown, WV: U.S. Department of Health and Human Services, Centers for Disease Control and Prevention, National Institute for Occupational Safety and Health, Fatality Assessment and Control Evaluation (FACE) Report F2009-06, https://www.cdc.gov/niosh/fire/ reports/face200906.html.

USFA [2015]. Firefighter fatalities in the United States in 2014. Washington, DC: U.S. Department of Homeland Security, Federal Emergency Management Association, U.S. Fire Administration, http://www.usfa.fema.gov/downloads/pdf/publications/ ff_fat14.pdf. 


\section{For More Information}

The National Fire Protection Association (NFPA) develops voluntary consensus standards for the fire service. A number of these standards describe the performance requirements for fire fighter trainees and fire service instructors. Available training and brief descriptions of NFPA standards for training and fitness can be viewed at http://www.nfpa.org/aboutthecodes/ list_of_codes_and_standards.asp.

The U.S. Fire Administration (USFA) maintains a website with related training and education courses offered by the National Fire Academy: https://www.usfa.fema.gov/training/.

The National Volunteer Fire Council (NVFC) maintains a website on training offered through the NVFC Academy: http://www.nvfc.org/training-digest-on-first-responderhealth-and-fitness/.

To receive documents or other information about occupational safety and health topics, contact NIOSH at

Telephone: 1-800-CDC-INFO (1-800-232-4636)

TTY: 1-888-232-6348 - E-mail: cdcinfo@cdc.gov

or visit the NIOSH website at www.cdc.gov/niosh.

For a monthly update on news at NIOSH, subscribe to NIOSH eNews by visiting www.cdc.gov/niosh/eNews.
Mention of any company or product does not constitute endorsement by NIOSH. In addition, citations to websites external to NIOSH do not constitute NIOSH endorsement of the sponsoring organizations or their programs or products. Furthermore, NIOSH is not responsible for the content of these websites.

This document is in the public domain and may be freely copied or reprinted. NIOSH encourages all readers of the Workplace Solutions to make them available to all interested employers and workers.

As part of the Centers for Disease Control and Prevention, NIOSH is the Federal agency responsible for conducting research and making recommendations to prevent workrelated illnesses and injuries. All Workplace Solutions are based on research studies that show how worker exposures to hazardous agents or activities can be significantly reduced.

\section{DHHS (NIOSH) Publication No. 2017-113}

Preventing Deaths and Injuries of Fire Fighters During Training Exercises

December 2016 